\title{
Quality of Life, Thyroid Function and Type of Surgery in Low Risk Thyroid Cancer
}

Cohen $\mathrm{MV}^{1}$, Bertoni $\mathrm{N}^{2}$, Nobre GM${ }^{3}$, Tramontin $\mathrm{MY}^{3}$, Andrade $\mathrm{FA}^{3}$, Alves Jr. $\mathbf{P A}^{3}$, de Fátima Teixeira $\mathbf{P}^{1}$, Bulzico $\mathbf{D A}^{3}$, Corbo $\mathbf{R}^{3}$, Vaisman $\mathbf{M}^{1}$ and Vaisman $F^{1,3 *}$

${ }^{1}$ Endocrinology, Faculdade de Medicina, Universidade Federal do Rio de J aneiro, Brazil

${ }^{2}$ Epidemiology Division Instituto Nacional do Cancer (INCa), Rio de J aneiro, Brazil

${ }^{3}$ Endocrinology-Instituto Nacional do Cancer (INCa), Rio de Janeiro, Brazil

*Corresponding author: Fernanda Vaisman, Praça Cruz Vermelha, 23, 80 andar-Centro, Rio deJ aneiro, Brazil

Received: April 21, 2021; Accepted: May 17, 2021; Published: May 24, 2021

\begin{abstract}
Background: Low risk thyroid cancer can be treated with lobectomy or total thyroidectomy. Studies have shown that the risk of recurrence does not differ between the two surgeries, although there are higher rates of complications with total thyroidectomy. Our study aimed to find if there were differences in quality of life and thyroid function in the two treatments.
\end{abstract}

Methods: Low risk DTC survivors answered three QoL questionnaires (EQ5D3L, SF36, and EORTC QLQ C30) and had their thyroid function evaluated.

Results: Twenty-six lobectomy patients and 101 total thyroidectomy were included. Hypoparathyroidism occurred more in the total thyroidectomy, and TSH was more likely to be on target (0.5-2.0) in lobectomy. There was no difference between groups regarding QoL, but there was a significant difference regarding thyroid function. In SF36 form, TSH off target led to more physical limitations, pain, less vitality, and worse social aspects. Abnormal total T3 level was associated with pain, less vitality, and worse mental health. In the EORTC QLQ C30, off target TSH led to worse role functioning, fatigue, and nausea. EQ5D form showed that worse utility index was found when TT3 was not in normal range.

Conclusion: This study showed there was a difference among thyroid function, specially TSH depending on type of surgery. When uncontrolled, TSH was associated with worse aspects of the quality of life. Therefore, lobectomy patients have a better thyroid function control and less surgical complications which might have an impact in some aspects of the quality of life when compared to total thyroidectomy.

Keywords: Thyroidectomy; Hypoparathyroidism; Differentiated thyroid carcinoma

\section{Introduction}

The prevalence of Differentiated Thyroid Carcinoma (DTC) is increasing worldwide. Currently, it's the fifth most common form of malignancy among Brazilian women [1]. Despite its low mortality, there's a high rate of recurrence/persistence, estimated at 20$30 \%$ [2]. Based on this, the American Thyroid Society (ATA), and other organizations (European thyroid society-ETA-and the Latin American thyroid society-LATS) classify DTCs according to this risk. Studies have shown that, in low-risk patients, 78-91 \% were disease free 10 years after surgery and Radioiodine Therapy (RIT). Other studies have confirmed these results, even with no RIT, identifying $1-2 \%$ of recurrent or persistent structural disease [3].

The choice of what type of surgery should be performed on these patients has been the subject of many discussions recently. Advantages of total thyroidectomy include easier follow-up and less uncertainty regarding the therapeutic response. However, there are some disadvantages. Surgical complications (anesthetic risk, unfavorable aesthetic result, and infection), vocal changes, hypoparathyroidism, and possible respiratory failure due to bilateral recurrent laryngeal nerve injury have greater risk in this type of surgery. Also, all patients undergoing total thyroidectomy will necessarily need thyroid hormone replacement [2]. Lobectomy, however, despite the difficulties in follow-up and the possibility of needing complementary surgery, in most cases (around 80\%) there is no need for hormone replacement. Additionally, complication risks are lower, and the cost is favorable $[2,4]$. As several studies have already shown, prognosis is similar among these patients regardless of the type of surgery $[2,5]$. It's up to the medical team, together with the patient, to balance the pros and cons of each surgery when choosing the treatment. Thus, the assessment of the patient's Health Related Quality of Life (HRQoL) is crucial for this decision.

Several studies have evaluated the HRQoL in DTC survivors, reporting a global drop in all parameters, with neuropsychometric assessments being the most relevant [6,7]. Some of these studies showed lower scores, for DTC patients compared to other neoplasms with worse prognosis and more aggressive treatments [6,7]. Factors that have been associated with a worse HRQoL include younger age, female, and lower educational level [6]. Still, there is instability in the HRQoL of patients, especially in the first 5 years after treatment6. However, there are conflicting results in the research already carried out. While some studies show a normalization of HRQoL after some time, others show that it doesn't completely normalize [6-9]. 
There are very few studies that evaluate patients with lobectomy, and even less that correlate the type of surgery with HRQoL. Since lobectomy is increasingly seen as a sufficient treatment for lowrisk DTCs, it is necessary to assess whether this surgery is better regarding HRQoL than total thyroidectomy. Furthermore, there are no studies that correlate thyroid function and HRQoL in patients treated for DTC specially when comparing the extent of surgery. With this, our study has the objective of evaluating HRQoL as well as thyroid function in patients with low-risk DTC treated with total thyroidectomy compared with the ones treated with less than total thyroidectomy.

\section{Methods}

This was an observational study, conducted in the National Institute of Cancer (INCa) in Rio de Janeiro. It included patients with low and low-intermediate risk DTC, over 18 years, with total or less than total thyroidectomy, no adjuvant therapy, and in active follow-up in this institution between August 2018 and August 2019 Exclusion criteria included: pregnancy; RIT; other primary cancers; and patients who couldn't answer the questionnaires due to cognitive impairment. After applying inclusion and exclusion criteria, the study population consisted of 127 patients, 101 with total, and 26 with partial thyroidectomy.

The patients were called for their routine consult, and before this, a trained physician applied 3 certified HRQoL questionnaires. The first, was the EQ-5D-3L, a generic questionnaire with 5 questions that give a utility index and a visual analogue scale ranging from 0 (worst) to 100 (best) [10]. Second, the SF-36, also a generic questionnaire, with 36 questions that assess 8 parameters: functional capacity; physical limitations; perception of pain; global health; vitality; social aspects; emotional aspects; and mental health [11]. Lastly, the EORTCQLQC30. It evaluates the HRQoL specifically in cancer patients assessing 4 aspects: quality and global health; functional status; symptoms; and financial difficulties regarding their disease [12]. All three questionnaires were validated in Portuguese and authorized to be used in this research by their creators.

After the questionnaires were applied, TSH, Free T4 (FT4), Total T3 (TT3), antiperoxidase, and antithyroglobulin were drawn. These parameters were measured by electrochemiluminescence. Reference value of TSH was 0.27 to $4.2 \mu \mathrm{UI} / \mathrm{mL}$, FT4 0.93 to $1.7 \mathrm{ng} / \mathrm{mL}$, TT3 70 to $120 \mathrm{ng} / \mathrm{mL}$. TPOantibody was normal if less than $34 \mathrm{U} / \mathrm{mL}$, and antithyroglobulin if less than $115 \mathrm{U} / \mathrm{mL}$.
We also asked about medications used, physical activity (in which less than 150 minutes per week was considered as sedentary), comorbidities, marital status, level of education, income (divided as A-more than 20 minimal wages/month, B-between 10-20 minimal wages/month, C-between 4-10 minimal wages/month, D-between 2-4 minimal wages/month, and E-less than 2 minimal wages/month), ethnicity, and menopausal status. In addition, a retrospective analysis of the patients' medical records was conducted regarding the tumor (histology, size, TNM stage and risk classification), the surgery (type, size of remnants if present based on the last ultrasound, and date of the surgery), and surgery complications, in which hypoparathyroidism was considered permanent when lasting more than six months and transitory when less than that.

Descriptive analysis of the sample characteristics was performed, and we compared sociodemographic and clinical characteristics of patients who underwent partial thyroidectomy and those who underwent total thyroidectomy, using Chi-squared and Fisher test.

The proportion of problem levels reported for each dimension of the EQ5D was compared between both groups of patients using Chi-squared/Fisher test. Descriptive analysis of VAS and utility score (calculated based on the valuation of the Brazilian population) 12129\} [13] were calculated and we compared the mean value of each patient group using $t$-Student test.

The EORTC raw scores of each scale were transformed to a score ranging from $0-100$, with higher scores representing either better functioning/QoL or more symptom/item burden according to the evaluated scale in the sample. EORTC and SF-36 scales means of patients with partial and total thyroidectomy were compared with $t$-Student test.

Also, we compared the HRQoL index/scores of patients considering $\mathrm{TSH}$, total $\mathrm{T} 3$ and free $\mathrm{T} 4$ results, independently of surgery type.

The significance level alpha of $5 \%$ was considered to test differences. All analyses were performed using the software R version 3.5.1.

This study was approved by the science and ethics committee of INCa and all patients involved signed a consent form before entering the study.

\section{Results}

After applying inclusion and exclusion criteria, as well as active

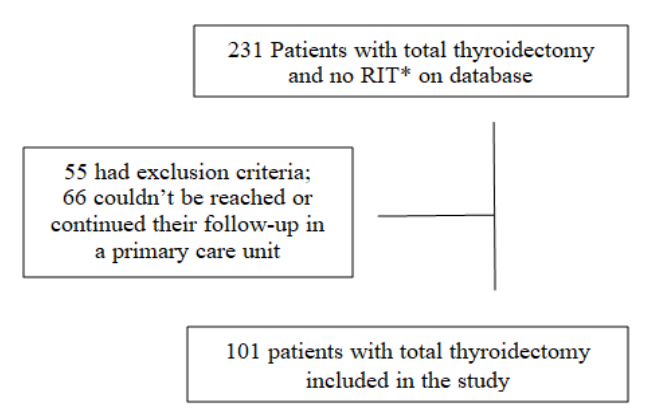

1 Patients with total thyroidectomy

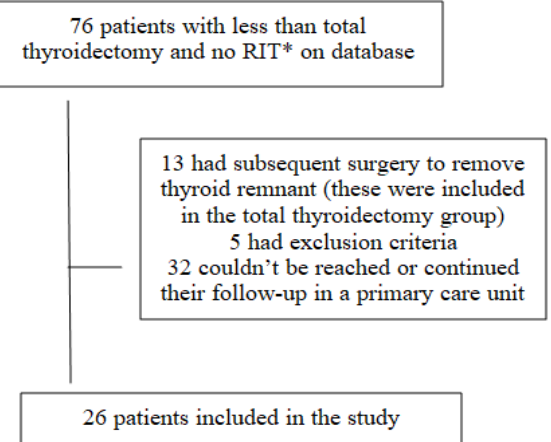

26 patients included in the study

Figure 1: Inclusion Diagram. 
Table 1: Characteristics of study population.

\begin{tabular}{|c|c|c|c|c|c|}
\hline & \multicolumn{2}{|c|}{ Lobectomy } & \multicolumn{2}{|c|}{ Total thyroidectomy } & \multirow{2}{*}{ p value* } \\
\hline & $\mathbf{N}$ & $\%$ & $\mathbf{n}$ & $\%$ & \\
\hline \multicolumn{6}{|l|}{ Age } \\
\hline$<40$ & 1 & 3.85 & 11 & 10.89 & \multirow{3}{*}{0.267} \\
\hline $40-59$ & 12 & 46.15 & 55 & 54.46 & \\
\hline 60 or more & 13 & 50 & 35 & 34.65 & \\
\hline \multicolumn{6}{|l|}{ Age (surgery) } \\
\hline$<40$ & 17 & 65.38 & 23 & 22.77 & \multirow{3}{*}{0} \\
\hline $40-59$ & 6 & 23.08 & 59 & 58.42 & \\
\hline 60 or more & 3 & 11.54 & 19 & 18.81 & \\
\hline \multicolumn{6}{|l|}{ Gender } \\
\hline Woman & 23 & 88.46 & 92 & 91.09 & \multirow{2}{*}{0.974} \\
\hline Man & 3 & 11.54 & 9 & 8.91 & \\
\hline \multicolumn{6}{|l|}{ Race } \\
\hline White & 19 & 73.08 & 50 & 49.5 & \multirow{3}{*}{0.055} \\
\hline Black & 0 & 0 & 11 & 10.89 & \\
\hline mixed (pardo) & 7 & 26.92 & 40 & 39.6 & \\
\hline \multicolumn{6}{|l|}{ Marital status } \\
\hline Married & 13 & 50 & 49 & 48.51 & \multirow{4}{*}{0.822} \\
\hline Divorced & 5 & 19.23 & 18 & 17.82 & \\
\hline Single & 4 & 15.38 & 23 & 22.77 & \\
\hline Widow & 4 & 15.38 & 11 & 10.89 & \\
\hline \multicolumn{6}{|l|}{ Schooling level } \\
\hline Up to Primary School & 8 & 30.77 & 39 & 38.61 & \multirow{3}{*}{0.687} \\
\hline High School & 10 & 38.46 & 38 & 37.62 & \\
\hline Undergraduate or higher & 8 & 30.77 & 24 & 23.76 & \\
\hline \multicolumn{6}{|l|}{ Social class } \\
\hline $\mathrm{A} / \mathrm{B} / \mathrm{C}$ & 3 & 12 & 11 & 10.89 & \\
\hline D & 12 & 48 & 38 & 37.62 & 0.576 \\
\hline E & 10 & 40 & 52 & 51.49 & \\
\hline \multicolumn{6}{|l|}{ Menopause } \\
\hline No & 8 & 30.77 & 40 & 39.6 & \multirow{2}{*}{0.547} \\
\hline Yes & 18 & 69.23 & 61 & 60.4 & \\
\hline \multicolumn{6}{|l|}{ Sedentary lifestyle } \\
\hline No & 12 & 46.15 & 32 & 34.78 & \multirow{2}{*}{0.407} \\
\hline Yes & 14 & 53.85 & 60 & 65.22 & \\
\hline \multicolumn{6}{|l|}{ BMI } \\
\hline normal $(18.5$ to <25) & 9 & 36 & 14 & 14.43 & \multirow{3}{*}{0.038} \\
\hline overweight (25 to <30) & 8 & 32 & 33 & 34.02 & \\
\hline obesity (30 or higher) & 8 & 32 & 50 & 51.55 & \\
\hline \multicolumn{6}{|l|}{ Antidepressant use } \\
\hline Yes & 6 & 23.08 & 15 & 14.85 & 0.477 \\
\hline No & 20 & 76.92 & 86 & 85.15 & 0.411 \\
\hline Anticonvulsant use & & & & & \\
\hline Yes & 1 & 3.85 & 1 & 0.99 & 0.369 \\
\hline No & 25 & 96.15 & 100 & 99.01 & 0.305 \\
\hline
\end{tabular}

${ }^{*}$ Chi-squared test or fisher test.
Table 2: Disease characteristics, comorbidities and thyroid function comparisons between lobectomy and total thyroidectomy groups.

\begin{tabular}{|c|c|c|c|c|c|}
\hline & \multicolumn{2}{|c|}{ Lobectomy } & \multicolumn{2}{|c|}{$\begin{array}{c}\text { Total } \\
\text { thyroidectomy }\end{array}$} & \multirow{2}{*}{ p value ${ }^{*}$} \\
\hline & $\mathbf{n}$ & $\%$ & $\mathbf{n}$ & $\%$ & \\
\hline \multicolumn{6}{|l|}{ Histology } \\
\hline Follicular & 1 & 3.85 & 5 & 4.95 & \multirow{2}{*}{1} \\
\hline Papillary & 25 & 96.15 & 96 & 95.05 & \\
\hline \multicolumn{6}{|l|}{ AJCC Stage } \\
\hline I & 26 & 100 & 97 & 96.04 & \multirow{2}{*}{0.581} \\
\hline$\| I-I I$ & 0 & 0 & 4 & 3.96 & \\
\hline \multicolumn{6}{|l|}{ ATA Risk } \\
\hline Low & 25 & 96.15 & 95 & 94.06 & \multirow{2}{*}{1} \\
\hline Intermediate & 1 & 3.85 & 6 & 5.94 & \\
\hline \multicolumn{6}{|c|}{ Hypertension } \\
\hline Yes & 13 & 50 & 55 & 54.46 & \multirow{2}{*}{0.853} \\
\hline No & 13 & 50 & 46 & 45.54 & \\
\hline \multicolumn{6}{|l|}{ Diabetes } \\
\hline Yes & 2 & 7.69 & 20 & 19.8 & \multirow{2}{*}{0.244} \\
\hline No & 24 & 92.31 & 81 & 80.2 & \\
\hline \multicolumn{6}{|c|}{ Surgical complications } \\
\hline Yes & 1 & 3.85 & $19^{\#}$ & 18.81 & \multirow{2}{*}{0.073} \\
\hline No & 25 & 96.15 & 82 & 81.19 & \\
\hline \multicolumn{6}{|c|}{ Hypoparathyroidism } \\
\hline Yes & 0 & 0 & 16 & 15.84 & \multirow{2}{*}{0.041} \\
\hline No & 26 & 100 & 85 & 84.16 & \\
\hline \multicolumn{6}{|c|}{ Vocal cord problems } \\
\hline Yes & 1 & 3.85 & 2 & 1.98 & \multirow{2}{*}{0.5} \\
\hline No & 25 & 96.15 & 99 & 98.02 & \\
\hline \multicolumn{6}{|l|}{ TSH } \\
\hline mean (SD) & $1.48(1.32)$ & & $2.73(6.79)$ & & 0.086 \\
\hline \multicolumn{6}{|c|}{$\begin{array}{l}\text { Total T3 (6 missing } \\
\text { values) }\end{array}$} \\
\hline mean (SD) & $97.4(24.2)$ & & $96.5(20.6)$ & & 0.868 \\
\hline \multicolumn{6}{|l|}{ Free T4 } \\
\hline mean (SD) & $1.41(0.23)$ & & $1.59(0.35)$ & & 0.003 \\
\hline
\end{tabular}

${ }^{*}$ Chi-squared test or $t$-test.

\#1 surgical complication not described in this table was a patient with tota thyroidectomy that had a spinal nerve lesion during surgery.

recruitment of patients that met all the norms of the study in our database, 127 patients with DTC entered the research, 26 with partial thyroidectomy (seen as lobectomy in the tables presented in this article) and 101 with total thyroidectomy (Figure 1). Table 1 describes the characteristics of the population of this study. Most patients were women $(88.46 \%$ with lobectomy and $91.09 \%$ with total thyroidectomy) and 40-59 years old with no difference between the groups. At the time of surgery, the population was also preferentially in the $40-59$ age groups (51.2\%). However, when analyzing the groups separately, it was seen that out of the patients with lobectomy, $65.38 \%$ were under 40 years old, while the patients with total thyroidectomy were mainly 40-59 years old (58,42\%). Other characteristics such as race, educational level, marital status, income, physical activity, 
Table 3: Thyroid function analysis as characterized by "normal" or "not normal" comparing patients with lobectomy and total thyroidectomy.

\begin{tabular}{|c|c|c|c|c|c|}
\hline & \multicolumn{2}{|c|}{ Lobectomy } & \multicolumn{2}{|c|}{ Total thyroidectomy } & \multirow{2}{*}{ p value* } \\
\hline & $\mathbf{n}$ & $\%$ & $\mathbf{n}$ & $\%$ & \\
\hline \multicolumn{6}{|l|}{ TSH } \\
\hline On target (0.5-2.0) & 15 & 57.69 & 28 & 27.72 & \multirow{2}{*}{0.008} \\
\hline Off target (<0.5 or >2.0) & 11 & 42.31 & 73 & 72.28 & \\
\hline \multicolumn{6}{|l|}{ T3T } \\
\hline normal (70-120) & 22 & 91.67 & 90 & 92.78 & \multirow{2}{*}{1} \\
\hline not normal $(<70$ or $>120)$ & 2 & 8.33 & 7 & 7.22 & \\
\hline \multicolumn{6}{|l|}{ T4L } \\
\hline normal (0.93-1.7) & 26 & 100 & 87 & 86.14 & \multirow{2}{*}{0.072} \\
\hline not normal $(<0.93$ or $>1.7)$ & 0 & 0 & 14 & 13.86 & \\
\hline
\end{tabular}

${ }^{*}$ Chi-squared test or $t$-test.

medications, and menopause didn't have any difference as well. However, the BMI analysis reached statistical differences when comparing the two groups. The group submitted to lobectomy had mostly a normal BMI (36\%), while total thyroidectomy group were predominantly obese $(51.55 \%)$.

Table 2 shows the characteristics of the tumor, comorbidities, surgical complications, and thyroid hormone levels. Both groups were similar regarding histology, staging, risk classifications, as well as comorbidities. Yet, hypoparathyroidism was more common in total thyroidectomy patients ( $\mathrm{p}$ 0.041). Other complications were vocal cord damage ( 1 patient in the lobectomy group and 2 patients in the total thyroidectomy group) and a spinal nerve lesion that happened in a patient during a total thyroidectomy surgery. When we evaluated thyroid function, TSH and TT3 were alike between the groups. Nonetheless, FT4 analysis showed a lower mean in the lobectomy group.

After assessing thyroid function in a global way, the groups were divided by hormonal values between normal and abnormal and a comparative analysis was performed in Table 3. TSH values between 0.5 and $2.0 \mathrm{mU} / \mathrm{L}$ were assigned as "on target" for monitoring low risk DTC according to the ATA3. Thus, in the lobectomy group, $57.7 \%$ had TSH on target, while in the total thyroidectomy group, this occurred in $27.7 \%$ ( $\mathrm{p}$ 0.008). If we analyze TSH according to the normal range of for the general population (i.e., 0.27 to $4.2 \mathrm{mU} / \mathrm{L}$ ) $38.6 \%$ of the patients with total thyroidectomy and $69.2 \%$ of the patients with a partial thyroidectomy had normal TSH. With TT3, 91.7\% of patients with lobectomy and $92.8 \%$ of patients with total thyroidectomy were in the "normal" group, with no statistical difference. As for FT4, 100\% of lobectomy patients and $86.1 \%$ of total thyroidectomy patients were normal without being statistically significant. This happened
Table 5: EQ-5D-3L Visual Analysis Scale (VAS) and utility index comparing lobectomy and total thyroidectomy patients.

\begin{tabular}{|l|c|c|c|c|c|c|}
\hline & \multicolumn{3}{|c|}{ VAS } & \multicolumn{3}{c|}{ Utility } \\
\hline & Lob. & Tot. & p value* & Lob. & Tot. & p value* \\
\hline Minimum & 20 & 10 & & 33 & 30.5 & \\
\hline Median & 77.5 & 80 & & 74.6 & 73.7 & \\
\hline Mean & 73.1 & 73.9 & 0.857 & 72.6 & 70.2 & 0.578 \\
\hline Maximum & 100 & 100 & & 100 & 100 & \\
\hline SD & 19.8 & 20.1 & & 20.2 & 15.8 & \\
\hline
\end{tabular}

Notes: Lob: Lobectomy; Tot: Total Thyroidectomy; SD: Standard Deviation; "t test.

Table 6: EORTC-QLQ-C30 analysis comparing lobectomy and total thyroidectomy

\begin{tabular}{|l|c|c|c|c|c|}
\hline \multirow{2}{*}{} & \multicolumn{2}{|c|}{ Lobectomy } & \multicolumn{2}{l}{ Total thyroidectomy } & \multirow{2}{*}{ p value* } \\
\cline { 2 - 5 } & Mean & SD & Mean & SD & \\
\hline Functional scales & & & & & \\
\hline Physical functioning & 79.7 & 20.9 & 78.9 & 21.8 & 0.864 \\
\hline Role functioning & 70.5 & 34.4 & 70.1 & 33.2 & 0.96 \\
\hline Emotional functioning & 65.1 & 32.5 & 55.6 & 33.3 & 0.196 \\
\hline Cognitive functioning & 67.3 & 33.2 & 59.6 & 33.1 & 0.295 \\
\hline Social functioning & 85.9 & 32.6 & 86.1 & 26.1 & 0.972 \\
\hline Symptom scaleslitems & & & & & \\
\hline Fatigue & 31.6 & 29.9 & 35.3 & 32.1 & 0.584 \\
\hline Nausea and vomiting & 10.9 & 21.1 & 11.4 & 18.5 & 0.915 \\
\hline Pain & 40.4 & 37.2 & 38.8 & 37.1 & 0.845 \\
\hline Dyspnea & 19.2 & 32.9 & 19.8 & 31.7 & 0.937 \\
\hline Insomnia & 39.7 & 37.7 & 41.3 & 41.4 & 0.859 \\
\hline Appetite loss & 14.1 & 30.1 & 13.9 & 26.4 & 0.97 \\
\hline Constipation & 20.5 & 34.1 & 23.4 & 37.3 & 0.705 \\
\hline Diarrhea & 14.1 & 25.3 & 12.2 & 27.4 & 0.74 \\
\hline Financial difficulties & 20.5 & 35.4 & 19.8 & 34.7 & 0.927 \\
\hline & & & & \\
\hline
\end{tabular}

t t test.

regardless of thyroid hormone replacement, since in our analysis, only one patient in the lobectomy group was not taking levothyroxine.

After, we analyzed the responses to the HRQoL questionnaires, starting with the EQ-5D-3L. This is shown in Table 4. Although in all categories the percentage of patients without problems was higher in the lobectomy group, there were no significant differences in any of them.

Looking at the visual analysis scale and the utility index in this inquiry, there was no difference between the groups, as seen in Table 5.

Table 4: Comparative analysis of the EQ-5D-3L questionnaires between lobectomy and total thyroidectomy.

\begin{tabular}{|c|c|c|c|c|c|c|c|c|c|c|c|c|c|c|c|}
\hline & \multicolumn{3}{|c|}{ Mobility } & \multicolumn{3}{|c|}{ Self-care } & \multicolumn{3}{|c|}{ Usual activities } & \multicolumn{3}{|c|}{ Pain/discomfort } & \multicolumn{3}{|c|}{ Anxiety/depression } \\
\hline & Lob & Tot & p value* & Lob & Tot & p value ${ }^{\star *}$ & Lob & Tot & p value* & Lob. & Tot. & p value* & Lob. & Tot. & p value* \\
\hline \multirow{2}{*}{$\begin{array}{l}\text { Level } 1 \\
\text { (no problems) }\end{array}$} & 22 & 76 & \multirow{4}{*}{0.31} & 26 & 97 & \multirow{4}{*}{0.581} & 19 & 72 & \multirow{4}{*}{0.857} & 11 & 34 & \multirow{4}{*}{0.411} & 9 & 27 & \multirow{4}{*}{0.426} \\
\hline & 84.6 & 75.3 & & 100 & 96 & & 73.1 & 71.3 & & 42.3 & 33.7 & & 34.6 & 26.7 & \\
\hline \multirow{2}{*}{$\begin{array}{l}\text { Levels } 2 \text { or } 3 \\
\text { (any problems) }\end{array}$} & 4 & 25 & & 0 & 4 & & 7 & 29 & & 15 & 67 & & 17 & 74 & \\
\hline & 15.4 & 24.8 & & 0 & 4 & & 26.9 & 28.7 & & 57.7 & 66.3 & & 65.4 & 73.3 & \\
\hline
\end{tabular}

Notes: Lob: Lobectomy; Tot: Total Thyroidectomy; ${ }^{*}$ Chi-squared test; **Fisher test 
Table 7: SF-36 comparison between patients with thyroid lobectomy and total thyroidectomy

\begin{tabular}{|l|c|c|c|c|c|}
\hline \multirow{2}{*}{} & \multicolumn{2}{|c|}{ Lobectomy } & \multicolumn{2}{l|}{ Total thyroidectomy } & \multirow{2}{*}{ p value* } \\
\cline { 2 - 6 } & Mean & SD & Mean & SD & \\
\hline Functional capacity & 70.4 & 29.6 & 74.3 & 23.9 & 0.536 \\
\hline Limitation - physical aspects & 53.8 & 42.8 & 53.7 & 42.6 & 0.989 \\
\hline Perception of pain & 49 & 25.2 & 55.2 & 28.4 & 0.281 \\
\hline General health & 62 & 24.9 & 68.2 & 21.7 & 0.251 \\
\hline Vitality & 51.7 & 26.3 & 50.5 & 26 & 0.838 \\
\hline Social aspects & 67.3 & 32.2 & 64.1 & 31.5 & 0.653 \\
\hline $\begin{array}{l}\text { Limitation - emotional } \\
\text { aspects }\end{array}$ & 60.3 & 46.2 & 61.4 & 42.6 & 0.911 \\
\hline Mental health & 64.9 & 21.2 & 58.4 & 25.6 & 0.189 \\
\hline
\end{tabular}

t t test.

The EORTC-QLQ-C30 analysis is exposed in Table 6. The mean and median scores for global health status were slightly higher in the lobectomy group, but it didn't reach statistical significance. Evaluating the symptoms, functional scale, financial and social difficulties regarding the treatment, there also wasn't any significant discrepancy between the groups.

Lastly, SF-36 was applied. Again, this questionnaire didn't show any significant disparity between the groups, as seen in Table 7.

Another part of this study was to associate thyroid function with each of the questionnaires. The SF-36 parameters and thyroid hormone levels associations are shown in tables 8. We observed that the "physical aspects", "pain perception", "vitality" and "social aspects" were scored inferiorly when TSH was off target with statistical significance. The other domains, however, although they also had a worse assessment when TSH was off target, didn't reach statistical significance. With TT3, values outside the normal limits made the perception of pain, vitality, and mental health worse compared to the patients who had normal levels, also with statistical significance. The other domains, like what happened with the TSH, were also lower when TT3 was abnormal, but without statistical significance. Finally, analyzing FT4, all domains were inferior when outside the reference limits. However, only the perception of pain and social aspects were significant in this analysis.

These same analyses were made with hormone levels and EORTCQLQ-C30. Starting with TSH, when analyzing the global health of the patients, worse outcomes were seen in patients with TSH off target with statistical significance. Mean global health score was 77.5 in patients with TSH on target and 69.2 when TSH was off ( $\mathrm{p}=0.047$ ). Table 8 shows that on the functional scale, it was obtained as a significant result, inferiority in the evaluation of role and cognitive functions in patients with TSH off target. In the symptoms scale, fatigue, and nausea, had a significant difference, appearing more in patients with TSH off target. The rest of the symptoms were also more common in patients with TSH off target, but without statistical significance. Regarding TT3, there was no difference in any aspects of the questionnaire. The FT4 analysis, however, showed a statistical difference in the emotional function, which was worse when the FT4 wasn't normal. There was also a significant difference when asked about the presence of nausea or dyspnea, these symptoms were more frequent when FT4 was abnormal.

Finally, the associations between the thyroid hormone levels and the EQ5D-VAS can be seen in Table 9. The assessment of VAS and the utility index weren't significantly different between the groups with TSH off target, although both were lower in the group with abnormal TSH. TT3 analysis showed no discrepancy in VAS, however, the Table 8: Eortc QLQ c30 analysis in association with TSH, TT3 and FT4.

\begin{tabular}{|c|c|c|c|c|c|c|c|c|c|c|c|c|c|c|c|}
\hline & \multirow{2}{*}{\multicolumn{2}{|c|}{$\begin{array}{c}\text { TSH } \\
\text { normal }\end{array}$}} & \multirow{2}{*}{\multicolumn{2}{|c|}{$\begin{array}{c}\begin{array}{c}\text { TSH not } \\
\text { normal }\end{array} \\
(<0.5 \text { or }>2.0)\end{array}$}} & \multirow{3}{*}{ p value ${ }^{*}$} & \multirow{2}{*}{\multicolumn{2}{|c|}{$\begin{array}{c}\text { T3T normal } \\
(70-210)\end{array}$}} & \multirow{2}{*}{\multicolumn{2}{|c|}{$\begin{array}{c}\text { T3T not normal } \\
(<70 \text { or }>210)\end{array}$}} & \multirow{3}{*}{ p value* } & \multirow{2}{*}{\multicolumn{2}{|c|}{$\begin{array}{c}\text { T4L normal } \\
(0.97-1.7)\end{array}$}} & \multirow{2}{*}{\multicolumn{2}{|c|}{\begin{tabular}{|c|} 
T4L not normal \\
$(<0.7$ or $>1.9)$ \\
\end{tabular}}} & \multirow{3}{*}{ p value* } \\
\hline & & & & & & & & & & & & & & & \\
\hline & Mean & SD & Mean & SD & & Mean & SD & Mean & SD & & Mean & SD & Mean & SD & \\
\hline \multicolumn{16}{|l|}{ Functional scales } \\
\hline Physical functioning & 82.6 & 18.8 & 77.3 & 22.7 & 0.162 & 81 & 19.8 & 68.1 & 30 & 0.239 & 79.9 & 20.9 & 72.9 & 25.9 & 0.345 \\
\hline Role functioning & 80.6 & 29.8 & 64.9 & 33.9 & 0.008 & 72.2 & 32.4 & 51.9 & 37.7 & 0.151 & 71.1 & 32.9 & 63.1 & 37.1 & 0.453 \\
\hline Emotional functioning & 63 & 32.5 & 54.8 & 33.5 & 0.185 & 60 & 32.6 & 38 & 35.9 & 0.108 & 60 & 31.9 & 37.5 & 37.9 & 0.05 \\
\hline Cognitive functioning & 74.4 & 27.3 & 54.4 & 33.9 & 0 & 61.9 & 31.8 & 64.8 & 41.2 & 0.841 & 62.7 & 33.1 & 48.8 & 31.7 & 0.143 \\
\hline Social functioning & 91.9 & 21.9 & 83.1 & 29.6 & 0.063 & 89.3 & 24.1 & 64.8 & 40.3 & 0.109 & 87.8 & 25.7 & 72.6 & 37.3 & 0.162 \\
\hline \multicolumn{16}{|l|}{ Symptom scales/items } \\
\hline Fatigue & 26.9 & 28.6 & 38.5 & 32.4 & 0.041 & 31.4 & 30.2 & 53.1 & 35.5 & 0.109 & 33.1 & 31.1 & 46 & 34.3 & 0.199 \\
\hline Nausea and vomiting & 7 & 16.8 & 13.5 & 19.8 & 0.054 & 10.3 & 18.5 & 16.7 & 20.4 & 0.386 & 9.4 & 17.9 & 26.2 & 21.4 & 0.013 \\
\hline Pain & 31.8 & 32.3 & 42.9 & 38.7 & 0.091 & 36.2 & 35.6 & 63 & 43.1 & 0.103 & 39.1 & 37.3 & 39.3 & 35.6 & 0.985 \\
\hline Dyspnea & 14.7 & 27.5 & 22.2 & 33.7 & 0.182 & 17.9 & 30.3 & 22.2 & 33.3 & 0.712 & 16.5 & 28.9 & 45.2 & 42.6 & 0.027 \\
\hline Insomnia & 32.6 & 40.2 & 45.2 & 40.3 & 0.096 & 39.3 & 40.3 & 48.1 & 41.2 & 0.549 & 41 & 40.1 & 40.5 & 45.6 & 0.968 \\
\hline Appetite loss & 10.9 & 22.7 & 15.5 & 29 & 0.326 & 11.9 & 24.9 & 22.2 & 28.9 & 0.325 & 13 & 26.1 & 21.4 & 33.6 & 0.379 \\
\hline Constipation & 14.7 & 32.8 & 27 & 37.8 & 0.062 & 19.9 & 33.9 & 40.7 & 46.5 & 0.222 & 21.2 & 35.1 & 35.7 & 46.2 & 0.275 \\
\hline Diarrhea & 10.1 & 23.6 & 13.9 & 28.4 & 0.425 & 11.3 & 25.5 & 18.5 & 29.4 & 0.493 & 10.6 & 24.5 & 28.6 & 38.9 & 0.114 \\
\hline Financial difficulties & 16.3 & 33.6 & 21.8 & 35.3 & 0.389 & 18.5 & 34.6 & 25.9 & 32.4 & 0.523 & 20.6 & 35.2 & 14.3 & 31.3 & 0.488 \\
\hline
\end{tabular}

t test. 
Table 9: EQ5D-VAS analysis in association with TSH, TT3 and FT4.

\begin{tabular}{|c|c|c|c|c|c|c|c|c|c|c|c|c|c|c|c|c|c|c|}
\hline & \multicolumn{3}{|c|}{ VAS } & \multicolumn{3}{|c|}{ Utility } & \multicolumn{3}{|c|}{ VAS } & \multicolumn{3}{|c|}{ Utility } & \multicolumn{3}{|c|}{ VAS } & \multicolumn{3}{|c|}{ Utility } \\
\hline & $\begin{array}{c}\text { TSH } \\
\text { on } \\
\text { target }\end{array}$ & $\begin{array}{c}\text { TSH } \\
\text { not on } \\
\text { target }\end{array}$ & \multirow{2}{*}{$\begin{array}{c}\mathbf{p} \\
\text { value }\end{array}$} & $\begin{array}{c}\text { TSH } \\
\text { on } \\
\text { target }\end{array}$ & $\begin{array}{c}\text { TSH } \\
\text { not on } \\
\text { target }\end{array}$ & \multirow{2}{*}{$\begin{array}{c}\mathbf{p} \\
\text { value }^{*}\end{array}$} & $\begin{array}{l}\text { Normal } \\
\text { TT3 }\end{array}$ & $\begin{array}{l}\text { Not normal } \\
\text { TT3 }\end{array}$ & \multirow{2}{*}{$\begin{array}{c}\mathbf{p} \\
\text { value }^{*}\end{array}$} & $\begin{array}{l}\text { Normal } \\
\text { TT3 }\end{array}$ & $\begin{array}{c}\text { Not normal } \\
\text { TT3 }\end{array}$ & \multirow{2}{*}{$\begin{array}{c}\mathbf{p} \\
\text { value }^{*}\end{array}$} & $\begin{array}{c}\text { Normal } \\
\text { FT4 }\end{array}$ & $\begin{array}{c}\text { Not normal } \\
\text { FT4 }\end{array}$ & \multirow{2}{*}{$\begin{array}{c}\mathbf{p} \\
\text { value }^{*}\end{array}$} & $\begin{array}{l}\text { Normal } \\
\text { FT4 }\end{array}$ & $\begin{array}{c}\text { Not normal } \\
\text { FT4 }\end{array}$ & \multirow{2}{*}{$\begin{array}{c}p \\
\text { value* }\end{array}$} \\
\hline & $\begin{array}{l}(0.5- \\
2.0)\end{array}$ & $\begin{array}{l}(<0.5 \text { or } \\
>2.0)\end{array}$ & & $\begin{array}{l}(0.5- \\
2.0)\end{array}$ & $\begin{array}{c}(<0.5 \text { or } \\
>2.0)\end{array}$ & & $\begin{array}{l}(70- \\
210)\end{array}$ & $\begin{array}{l}(<70 \text { or } \\
>210)\end{array}$ & & $\begin{array}{l}(70- \\
210)\end{array}$ & $\begin{array}{l}(<70 \text { or } \\
>210)\end{array}$ & & $\begin{array}{l}(0.93- \\
1.7)\end{array}$ & $\begin{array}{l}(<0.93 \\
\text { or }>1.7)\end{array}$ & & $\begin{array}{l}(0.93- \\
1.7)\end{array}$ & $\begin{array}{c}(<0.93 \text { or } \\
>1.7)\end{array}$ & \\
\hline Minimum & 20 & 10 & \multirow{5}{*}{0.481} & 30.5 & 33 & \multirow{5}{*}{0.301} & 10 & 50 & \multirow{5}{*}{0.975} & 30.5 & 37.1 & \multirow{5}{*}{0.027} & 10 & 40 & \multirow{5}{*}{0.09} & 30.5 & 47.5 & \multirow{5}{*}{0.67} \\
\hline Median & 80 & 77.5 & & 73.7 & 73.7 & & 80 & 70 & & 73.7 & 63.4 & & 80 & 65 & & 73.7 & 63.8 & \\
\hline Mean & 75.4 & 72.8 & & 73 & 69.6 & & 74.2 & 74.4 & & 72.6 & 59.2 & & 74.8 & 65 & & 71 & 68.6 & \\
\hline Maximum & 100 & 100 & & 100 & 100 & & 100 & 100 & & 100 & 80,1 & & 100 & 100 & & 100 & 100 & \\
\hline SD & 18.9 & 20.6 & & 17.8 & 16.2 & & 20 & 17.4 & & 16 & 14.7 & & 19.9 & 19.1 & & 16.4 & 20 & \\
\hline
\end{tabular}

"t test.

utility index was worse in the group with abnormal TT3 (p 0.027).

With FT4, both parameters were lower in the group with abnormal values, although there was no statistical relevance.

\section{Discussion}

Our findings showed that, as expected by earlier studies, hypoparathyroidism happened more in patients with total thyroidectomy $[2,3,14]$. Another significant result was that patients with lobectomy were more likely to have TSH on target regardless of thyroid hormone replacement or not, which we believe is due to some thyroid hormone secretion by the remnant thyroid tissue. This study also found that, in two of the HRQoL questionnaires, off target TSH was related to worse outcomes. In SF-36 this was specially seen in physical aspects, perception of pain, vitality, and social aspects. In the EORTC-QLQ-c30, global health status, role aspects, cognitive function, fatigue, and nausea had a worse evaluation by the patients with off target TSH. Abnormal FT4 was associated with worse emotional function in one of the questionnaires, and abnormal TT3 was associated with worse perception of pain, vitality, mental health, and utility. A previous research conducted by Morón-Díaz et al. presented a correlation between higher TSH and worst HRQoL even when TSH was within the normal range in patients with primary hypothyroidism treated with levothyroxine [15]. With these results, we can aspire to think that, since off target TSH has worse outcomes in several HRQoL aspects, and there is a higher probability that patients with total thyroidectomy will have worse TSH control, it is possible that patients with total thyroidectomy might have issues with HRQoL at some point of their follow-up, even though it wasn 't the case in this study.

Although there wasn't a significant difference between the groups among the HRQoL questionnaires, there was a tendency to be better among the lobectomy group. This result was also shown in an earlier study by a Canadian group that compared HRQoL in patients with low-risk DTC submitted to total or hemithyroidectomy [16]. However, they did not evaluate thyroid hormones. Also, in that study, the authors found that there was a lack of validation for patients with low-risk DTC as well as an absence of reference values for this specific population in a variety of HRQoL questionnaires [16]. On the other hand, Nickel B, et al. conducted a study with opened label questions about quality of life in patients treated for DTC and compared the responses with the extension of surgery. Their findings showed that the group with total thyroidectomy had a 1.5 greater chance of having HRQoL issues or surgical complications compared to a less aggressive approach [14]. Nonetheless, this study included patients with intermediate and high risk, as well as patients with RIT [14]. Yet, Hedman C, et al. demonstrated that though all patients with DTC have a worse HRQoL than the general population, patients submitted to hemithyroidectomy had more fear of recurrence than patients with total thyroidectomy which could affect their quality of life negatively. But this fear was weakened after one year of follow-up [17].

There was a study that analyzed the relation between thyroid hormone levels and HRQoL with DTC patients and didn 't find any differences [18]. Different from our study, however, they evaluated only patients with total thyroidectomy and RIT which has been proven to be a factor to aggravate quality of life [2].

Although some studies have shown that, in primary hypothyroidism, subnormal TT3 values may be present and responsible for persistence of symptoms in patients considered euthyroid, suggesting that in those cases $\mathrm{T} 4$ and $\mathrm{T} 3$ replacement may be considered, our study showed that, in patients with normal TSH, TT3 levels didn't affect HRQoL in a significant way. This goes in agreement with other studies that showed no difference in HRQoL when combined thyroid hormone replacement therapy was applied $[19,20]$.

Still, our study had some limitations. INCa is specialized cancer center that receives patients from all over the country. This way, patients that aren't taking any drugs or have already been disease free for a long time, have the option to continue their follow up in a primary care unit near their house. This could be the reason why nearly all patients with lobectomy, in this study, were taking levothyroxine, which isn't the scenery reported in most studies [2]. Again, the patients that continue to follow up in our institution might be the ones that have more insecurity about their disease which could also affect their HRQoL. Nonetheless, our study was conducted in an institution with highly experienced endocrinologists, specialized in thyroid cancer and had trained physicians apply all the questionnaires in person, which eliminates a possible bias of understanding the questions. Also, we applied 3 different questionnaires that have similar questions which reinforces the validity of the methodology in our opinion.

Thus, this study suggests that patients with thyroid lobectomy have a better thyroid function control and this might have a positive impact in HRQoL. We propose that further studies with a grater population, especially with a greater number of lobectomy patients, be conducted to further corroborate our findings.

To our knowledge, this is the first study to compare HRQoL, 
thyroid function, and correlate these parameters in patients with low or intermediate-low risk DTC separated by the extent of the surgery they were submitted to. In Brazil, as well, there aren `t any studies that compare DTC patients who underwent thyroid lobectomy to total thyroidectomy.

\section{Conclusion}

This study compared low risk DTC patients with thyroid lobectomy and total thyroidectomy. Although our study didn't find significant difference in the HRQoL questionnaires, there was a difference among thyroid function, specially TSH. This hormone, when off target, was associated with worse aspects of HRQoL. There was also more hypoparathyroidism among patients with total thyroidectomy. With this, we can conclude that patients submitted to lobectomy have a better thyroid function control in addition to less surgical complications and this might have an impact in some aspects of the QoL when compared to patients submitted to total thyroidectomy.

\section{References}

1. Incidência de Câncer no Brasil. 2020

2. Haymart MR, et al. Controversies in the management of low risk differentiated thyroid cancer. Endocrine reviews. 2017; 38: 351-378.

3. Haugen BR, et al. American Thyroid Association management guidelines fo adult patients with thyroid nodules and differentiated thyroid cancer. Thyroid 2016; 26: 1-133.

4. Lang $\mathrm{BH}$, et al. Lobectomy is a more cost-effective option than tota thyroidectomy for 1-4 $\mathrm{cm}$ papillary thyroid carcinoma that do not possess clinical recognizable high-risk features. Ann Surg Oncology. 2016; 23: 3641 3652.

5. Kwon $\mathrm{H}$, et al. Comparison of lobectomy and total thyroidectomy in patients with papillary thyroid microcarcinoma - a retrospective individual risk factormatches cohort study. European Journal of Endocrinology. 2017; 176: 371 378.

6. Aschebrook-Kilfoy B, et al. Risk factors for decreased quality of life in thyroid cancer survivors: Initial findings from the North American thyroid cancer survivorship study. Thyroid. 2015; 12: 1313-1321.

7. Schultz PN et al. Health profiles and quality of life of 518 survivors of thyroid cancer. Head and Neck. 2003; 25: 349-356.
8. Lubitz, et al. Measurement and variation in estimation of quality of life effects of patients undergoing treatment for papillary thyroid carcinoma. Thyroid. 2017; 27: 197-206.

9. Juxiang Gou MS, et al. Health-related quality of life assessment in surgical patients with papillary thyroid carcinoma - A single center analysis from mainland China. Medicine (Baltimore). 2017; 96: e8070.

10. EuroQol Group. EuroQol--a new facility for the measurement of healthrelated quality of life. Health Policy. 1990; 16: 199-208.

11. Taft C, Karlsson J, Sullivan M. Do SF-36 summary component scores accurately summarize subscale scores? Qual Life Res. 2001; 10: 395-404.

12. Aaronson NK, Ahmedzai S, Bergman B, Bullinger M, Cull A, Duez NJ, et al. The European Organization for Research and Treatment of Cancer QLQ-C30: a quality-of-life instrument for use in international clinical trials in oncology. J Natl Cancer Inst. 1993; 85: 365-376.

13. Santos M, Cintra MA, Monteiro AL, Santos B, Gusmão-Filho F, Andrade MV, et al. Brazilian Valuation of EQ-5D-3L Health States: Results from a Saturation Study. Med Decis Making. 2016; 36: 253-263.

14. Nickel B, Tan T, Cvejic E, et al. Health-Related Quality of Life After Diagnosis and Treatment of Differentiated Thyroid Cancer and Association With Type of Surgical Treatment. JAMA Otolaryngol Head Neck Surg. 2019; 145: 231-238.

15. Morón-Díaz M, Saavedra $P$, Alberiche-Ruano MP, Rodríguez-Pérez CA, López-Plasencia $Y$, Marrero-Arencibia D, et al. Correlation between TSH levels and quality of life among subjects with well-controlled primary hypothyroidism. Endocrine. 2020.

16. Bongers PJ, Greenberg CA, Hsiao R, et al. Differences in long-term quality of life between hemithyroidectomy and total thyroidectomy in patients treated for low-risk differentiated thyroid carcinoma. Surgery. 2020; 167: 94-101.

17. Hedman C, Djärv T, Strang P, Lundgren Cl. Fear of Recurrence and View of Life Affect Health-Related Quality of Life in Patients with Differentiated Thyroid Carcinoma: A Prospective Swedish Population-Based Study. Thyroid. 2018

18. Massolt ET, van der Windt M, Korevaar TI, et al. Thyroid hormone and its metabolites in relation to quality of life in patients treated for differentiated thyroid cancer. Clin Endocrinol (Oxf). 2016; 85: 781-788.

19. Ettleson MD, Bianco AC. Individualized Therapy for Hypothyroidism: Is T4 Enough for Everyone? J Clin Endocrinol Metab. 2020; 105: e3090-e3104.

20. Siegmund W, Spieker K, Weike AI, Giessmann T, Modess C, Dabers T, et al. Replacement therapy with levothyroxine plus triiodothyronine (bioavailable molar ratio $14: 1$ ) is not superior to thyroxine alone to improve well-being and cognitive performance in hypothyroidism. Clin Endocrinol (Oxf). 2004; 60: $750-757$. 